\title{
High-Grade, Low Prostate-Specific Antigen Prostate Cancer: Unique Hormone-Resistant Entity with Poor Survival
}

Prostate cancer is usually highly androgen-dependent and exquisitely responsive to androgen deprivation therapy (ADT). In addition, prostate-specific antigen (PSA) production is positively regulated by androgens. ${ }^{[1]}$ Although PSA is classically elevated in high-grade disease, some patients present with the inharmonious scenario of high-grade disease and low PSA. Low-PSA, high-grade disease may represent a unique entity with underlying dedifferentiated biology, and as such may respond poorly to the current standard treatments, particularly ADT and is associated with high rates of prostate cancer-specific mortality.

As a general rule, low-PSA-producing, high-grade prostate cancer is neuroendocrine prostate cancer, including the small-cell variant, which represents an aggressive hormone-resistant entity. ${ }^{[2-5]}$ In patients diagnosed pathologically as having either large cell or small cell neuroendocrine carcinoma, the prognosis is even poorer. As an example, in a series of 241 cases identified from the Surveillance, Epidemiology, and End Results (SEER) database over a 30-year period, 60\% had metastatic disease at presentation. The 1, 2, and 5-year survival rates for the entire series were, respectively, $48 \%, 28 \%$, and $14 \%{ }^{[6]}$ Mahal et al. analyzed differences in values for 62 prostate cancer transcriptomic signatures in the decipher genomics resource information database; including signatures related to prognosis, ${ }^{[7]}$ androgen receptor (AR) signaling, ${ }^{[8]}$ and neuroendocrine/small-cell prostate cancer. ${ }^{[9]}$ After manifold testing adjustment, Gleason 8-10 tumors with PSA $\leq 2.5 \mathrm{ng} / \mathrm{ml}$ were more likely to be associated with neuroendocrine/small-cell genomic signatures and less likely to be associated with an AR signaling signature compared to Gleason 8-10 tumors with PSA >2.5 ng/ ml (both $P=0.046$ ). No such association was seen for Gleason $\leq 7$ tumors.

Imperative differences in the clinical and prognostic characteristics of these patients are illustrated by an analysis that included almost 500,000 men with T1-4N0M0 prostate cancer from the National Cancer Database (NCDB) and 136,000 men from the SEER database. In the by and large NCDB series, $0.7 \%$ of patients had Gleason 8-10 disease and a PSA $\leq 2.5 \mathrm{ng} / \mathrm{dL}$. Among those with Gleason 8-10 disease, $6 \%$ had a PSA $\leq 2.5 \mathrm{ng} / \mathrm{dL} .{ }^{[10]}$ In the SEER record, prostate cancer-specific mortality was higher for men with a PSA $\leq 2.5 \mathrm{ng} / \mathrm{dL}$ and Gleason 8-10 adenocarcinomas compared with the reference group of those with a PSA 4.1-10.0 ng/dL at diagnosis (hazard ratio [HR] 2.70), and it was similar to that for men with high-grade disease and a PSA $>20 \mathrm{ng} / \mathrm{dL}$ (HR 2.56 compared with the reference group). The adjusted prostate cancer-specific mortality rate at 47 months after diagnosis was $14.0 \%$ in the high-grade, low-PSA subset, compared with $4.9 \%$ in those with a PSA $>2.5 \mathrm{ng} / \mathrm{dL} .{ }^{[11]}$

Among men with high-grade disease and a low PSA treated with radiation therapy, the use of androgen deprivation therapy was associated with an overall survival benefit for those with a PSA $>2.5 \mathrm{ng} / \mathrm{dL}$ but not for those with a PSA $\leq 2.5 \mathrm{ng} / \mathrm{dL} \cdot{ }^{[12]}$

Given the biological heterogeneity of prostate cancer and its multifocality, it is hypothesized that tumors with a higher Gleason grade have a higher chance for occurrence of a clonal shift in the original tumor that may express the features of other prostate cancers, including biological aggressiveness, and that such tumors may be associated with to be deficient in PSA production. The phenomenon of prostate cancer progression with unrelated PSA elevation may be explained by the proliferation of cell lines that either cannot produce PSA or are poorly differentiated prostate cancer cells that have lost their capacity to express PSA. In addition, these findings also highlight the potential difficulties with detecting this unique aggressive entity, which would not necessarily be diagnosed with PSA screening as the PSA levels would typically be below the threshold to biopsy. Thus, it is likely that such patients with aggressive cancers could be diagnosed based on some combination of clinical symptoms, presentation, digital rectal examination, imaging, and PSA kinetics.

Since low-PSA, high-grade disease tends to be late-presenting given that low PSA does not typically prompt a biopsy, the development of supplementary biomarkers to aid in early detection of aggressive and poorly differentiated disease is necessary. Furthermore, whether low-PSA, high-grade tumors are a heterogeneous entity with a mixture of tumor types such as aggressive neuroendocrine and more standard-risk prostate adenocarcinoma would need to be determined in developing new approaches to this disease. In a study by Sella et al., on 18 patients with clinically progressive androgen-independent prostate cancer with low PSA levels, each patient demonstrated elevation of at least one tumor marker, such as CA 19-9, CEA, CA 125, and CA 15-3. The tumor cells were immunoreactive for neuroendocrine markers in all specimens. They found that a low serum PSA level and progressive androgen-independent prostate cancer was characterized by a high proportion of lytic bone disease, visceral metastasis, the histological features of small cell or poorly differentiated prostate cancer and sensitivity to cisplatin-based chemotherapy. ${ }^{[13]}$ Nishio 
et al. also reported that serum CEA, CA 19-9, and CA 15-3 were elevated in patients with metastatic prostate cancer who had normal serum PSA levels. ${ }^{[14]}$

Although the clinical presentation of these prostate cancers when they present with localized disease is similar to that of other prostate cancers, metastases often occur early in the natural history, and symptoms can be due to distant disease. In addition, a range of laboratory abnormalities have been reported with the small cell variant, including paraneoplastic syndromes such as Cushing's syndrome, peripheral neuropathy, membranous nephropathy, and hypercalcemia.

In moving toward the treatment guidelines, one hypothesis is that patients with low-PSA, high-grade disease may be the group that would benefit the most from addition of chemotherapy to standard hormonal therapy for high-risk localized disease, on the basis of new randomized evidence showing the benefit of chemoradiotherapy in localized high-risk disease. ${ }^{[15,16]}$ While docetaxel has been favored as the chemotherapy of choice for high-risk localized disease, a platinum-based agent could also be considered in the setting of a clinical trial given the neuroendocrine expression features. It has been demonstrated that neuroendocrine prostate cancer has significant over expression and amplification of specific markers, and there are ongoing phase 2 studies evaluating the efficacy of targeted inhibition in the metastatic setting (NCT01799278). Depending on the results of this study, the expansion of targeted inhibition for patients with low-PSA, high-grade disease in an investigative setting may be appropriate. Finally, it should be noted that an alternative surveillance strategy to PSA monitoring that involves imaging may be needed.

The optimal management of patients with high-grade, low-PSA prostate cancer has not been well defined, and the clinical observations in these patients suggest that the standard approach to high-risk and very high-risk disease may not be optimal. Clinicians should be aware of these findings, and these patients should be considered for additional molecular markers, systemic staging, and clinical trials studying the use of chemotherapy and other novel agents for very high-risk prostate cancers.

\section{Vikash Kumar}

Department of Radiation Oncology, Asian Institute of Medical Sciences, Faridabad, Haryana, India

Address for correspondence: Dr. Vikash Kumar, Department of Radiation Oncology, Asian Institute of Medical Sciences, Faridabad - 122 001, Haryana, India. E-mail:drvikashkr@gmail.com
Submitted: $12-\mathrm{Feb}-2020$

Revised: 19-Jun-2020

Accepted: 30-Jun-2020

Published: 29-Aug-2020

\section{References}

1. Kim J, Coetzee GA. Prostate specific antigen gene regulation by androgen receptor. J Cell Biochem 2004;93:233-41.

2. Aggarwal R, Zhang T, Small EJ, Armstrong AJ. Neuroendocrine prostate cancer: Subtypes, biology, and clinical outcomes. J Natl Compr Canc Netw 2014;12:719-26.

3. Hirano D, Okada Y, Minei S, Takimoto $\mathrm{Y}$, Nemoto $\mathrm{N}$. Neuroendocrine differentiation in hormone refractory prostate cancer following androgen deprivation therapy. Eur Urol 2004;45:586-92.

4. Epstein JI, Amin MB, Beltran H, Lotan TL, Mosquera JM, Reuter VE, et al. Proposed morphologic classification of prostate cancer with neuroendocrine differentiation. Am J Surg Pathol 2014;38:756-67.

5. Beltran H, Rickman DS, Park K, Chae SS, Sboner A, MacDonald TY, et al. Molecular characterization of neuroendocrine prostate cancer and identification of new drug targets. Cancer Discov 2011;1:487-95.

6. Deorah S, Rao MB, Raman R, Gaitonde K, Donovan JF. Survival of patients with small cell carcinoma of the prostate during 1973-2003: A population-based study. BJU Int 2012;109:824-30.

7. Mahal BA, Aizer AA, Efstathiou JA, Nguyen PL. Association of very low prostate-specific antigen levels with increased cancer-specific death in men with high-grade prostate cancer. Cancer 2016;122:78-83.

8. Alshalalfa M, Santiago Jimenez $M$, Erho N, Fishbane N, Yousefi K, Al-Deen AH, et al. Relationships between an androgen receptor output signature (ARoS), AR expression, and poor prostate cancer prognosis in RP tissues. J Clin Oncol 2017;6 Suppl 35:38.

9. Alshalalfa M, Tsai H, Haddad Z, Ross A, Karnes RJ, Davicioni E, et al. Deciphering the genomic fingerprint of small cell prostate cancer with potential clinical utility. J Clin Oncol 2016;2 Suppl 34:303.

10. Bilimoria KY, Stewart AK, Winchester DP, Ko CY. The national cancer data base: A powerful initiative to improve cancer care in the United States. Ann Surg Oncol 2008;15:683-90.

11. National Cancer Institute. Overview of the SEER Program. Available from: https://seer.cancer.gov/about/overview.html. [Last accessed on 2020 Jul 17].

12. National Cancer Institute. PSA values and SEER data. Available from: https://seer.cancer.gov/data/psa-values.html. [Last accessed on $2020 \mathrm{Jul} 17]$.

13. Sella A, Konichezky M, Flex D, Sulkes A, Baniel J. Low PSA metastatic androgen-independent prostate cancer. Eur Urol 2000;38:250-4.

14. Nishio R, Furuya Y, Nagakawa O, Fuse H. Metastatic prostate cancer with normal level of serum prostate-specific antigen. Int Urol Nephrol 2003;35:189-92.

15. Sandler HM, Hu C, Rosenthal SA, Sartor O, Gomell LG, et al. A phase III protocol of androgen suppression (AS) and 3DCRT/IMRT versus AS and 3DCRT/IMRT followed 
by chemotherapy (CT) with docetaxel and prednisone for localized, high-risk prostate cancer (RTOG 0521). J Clin Oncol 2015;18 Suppl 33:LBA5002.

16. James ND, Sydes MR, Clarke NW, Mason MD, Dearnaley DP, Spears MR, et al. Addition of docetaxel, zoledronic acid, or both to first-line long-term hormone therapy in prostate cancer (STAMPEDE): Survival results from an adaptive, multiarm, multistage, platform randomised controlled trial. Lancet 2016;387:1163-77.
This is an open access journal, and articles are distributed under the terms of the Creative Commons Attribution-NonCommercial-ShareAlike 4.0 License, which allows others to remix, tweak, and build upon the work non-commercially, as long as appropriate credit is given and the new creations are licensed under the identical terms.

\begin{tabular}{|l|l|}
\hline \multicolumn{2}{|c|}{ Access this article online } \\
\hline Quick Response Code: & Website: \\
& www.ijmpo.org \\
\cline { 2 - 2 } & DOI: \\
\hline
\end{tabular}

How to cite this article: Kumar V. High-grade, low prostate-specific antigen prostate cancer: Unique hormone-resistant entity with poor survival. Indian J Med Paediatr Oncol 2020;41:481-3. 